\title{
On the Use of Potential Denaturing Agents for Ethanol in Direct Ethanol Fuel Cells
}

\author{
Domnik Bayer, ${ }^{1}$ Florina Jung, ${ }^{1}$ Birgit Kintzel, ${ }^{1}$ Martin Joos, ${ }^{1}$ Carsten Cremers, ${ }^{1}$ \\ Dierk Martin, ${ }^{2}$ Jörg Bernard, ${ }^{2}$ and Jens Tübke ${ }^{1}$ \\ ${ }^{1}$ Department of Applied Electrochemistry, Fraunhofer-Institute for Chemical Technology ICT, Joseph-von-Fraunhofer-Straße 7 , \\ 76327 Pfinztal, Germany \\ ${ }^{2}$ Südzucker AG Mannheim/Ochsenfurt, Central Department Research, Development \& Technological Services, Wormser Straße 11, \\ 67283 Obrigheim, Germany
}

Correspondence should be addressed to Domnik Bayer, domnik.bayer@ict.fraunhofer.de

Received 12 March 2011; Accepted 4 May 2011

Academic Editor: Dingsheng Yuan

Copyright (๑) 2011 Domnik Bayer et al. This is an open access article distributed under the Creative Commons Attribution License, which permits unrestricted use, distribution, and reproduction in any medium, provided the original work is properly cited.

Acidic or alkaline direct ethanol fuel cells (DEFCs) can be a sustainable alternative for power generation if they are fuelled with bioethanol. However, in order to keep the fuel cheap, ethanol has to be exempted from tax on spirits by denaturing. In this investigation the potential denaturing agents fusel oil, tert-butyl ethyl ether, and Bitrex were tested with regard to their compatibility with fuel cells. Experiments were carried out both in sulphuric acid and potassium hydroxide solution. Beside, basic electrochemical tests, differential electrochemical mass spectrometry (DEMS) and fuel cell tests were conducted. It was found that fusel oil is not suitable as denaturing agent for DEFC. However, tert-butyl ethyl ether does not seem to hinder the ethanol conversion as much. Finally, a mixture of tert-butyl ethyl ether and Bitrex can be proposed as promising candidate as denaturing agent for use in acidic and alkaline DEFC.

\section{Introduction}

As fossil fuels run short and the problem of environmental pollution is getting serious, fuel cells offer an alternative of clean and sustainable power generation. Especially direct alcohol fuel cells (DAFCs) show a high potential as power supply for small portable devices $[1,2]$. In comparison to hydrogen fuelled polymer electrolyte fuel cells (PEMFCs), they offer the advantage of an easy fuel distribution and a high volumetric and gravimetric energy density of the fuel. Direct methanol fuel cells (DMFCs) are widely investigated and have already entered the market. However, ethanol as fuel for DAFCs has some serious advantages compared to methanol. Besides its higher gravimetric energy density and boiling point, and its lower vapour pressure, ethanol is less toxic than methanol. Furthermore, methanol is classified as chemical whereas ethanol is already available to consumers almost everywhere in its denatured form. Denatured ethanol is not only available to the public in retail stores; but is also exempted from tax on spirits and thus a rather cheap fuel. Another advantage of ethanol is that it can easily be produced in large quantities from renewable raw materials by fermentation.

However, apart from all the advantages of ethanol as fuel, its electro-catalysis in fuel cells is still subject to research. This is especially true for the alkaline medium [3]. Furthermore, in order to denature ethanol, adding an inappropriate chemical as denaturing agent can either cause serious catalyst poisoning or membrane damage in the fuel cell [4]. Thus, an appropriate denaturing agent which is compatible with DEFC has to be chosen carefully.

In the present study, potential denaturing agents have been chosen with regard to their use in DEFC and with respect to the regulations of the German custom authorities. A suitable denaturing agent should be converted along with ethanol or should not hinder the ethanol conversion. A complete conversion of the denaturing agent along with ethanol would allow restoring the energy density of ethanol. Should the denaturing agent not hinder the ethanol conversion by being inert, the energy density of ethanol would be 
reduced by adding such an inert denaturing agent. However, as denaturing agents are usually added in small quantities, the loss in energy density would probably be tolerable.

In order to assess potential denaturing agents, a first choice was made according to the physical and chemical properties of substances as well as customs regulations. The chosen substances were first investigated with basic electrochemical techniques at platinum as model catalyst in acidic and alkaline environments. Despite its high price, platinum is still part of most current fuel cell catalysts as it is the most active monometallic catalyst. Furthermore, platinum is very sensitive towards poisoning. Thus, the compatibility with platinum is a first prerequisite for a potential denaturing agent. Promising candidates were further tested in an electrochemical cell at carbon-supported commercial fuel cell catalysts coated on inert titanium electrodes. The most promising candidate is finally investigated in an actual fuel cell with regard to compatibility with the whole system.

\section{Experimental}

The electrochemical experiments were performed in threeelectrode configuration in a glass cell which can be refilled from the top and drained through a bottom valve. This enabled an electrolyte exchange without losing the control of the potential of the working electrode. In order to get a first impression of the electrochemical activities of all investigated denaturing agents, a platinum foil electrode of the geometric area of $1 \mathrm{~cm}^{2}$ was used as working electrode, while a platinised platinum electrode of a larger area served as counter electrode. Later on, as described below, the most promising candidates as denaturing agents were as well tested in this setup using a carbon-supported platinumtin and a carbon-supported nonplatinum catalyst. In acidic medium, a mercury/mercury sulphate electrode (MMS, $+0,682 \mathrm{~V}$ versus RHE) was used as reference electrode, in alkaline medium a mercury/mercury oxide electrode (MMO, $+0,880 \mathrm{~V}$ versus RHE) was employed to determine the potential of the working electrode. However, all potentials in this work are referenced to the RHE scale. The electrodes were connected to an EG\&G 273 potentiostat controlled by a personal computer equipped with Scribner Corr Ware software. The base electrolytes $0.5 \mathrm{M}$ sulphuric acid and $0.1 \mathrm{M}$ potassium hydroxide solution were prepared from Merck chemicals. In case of the acidic solution, concentrated sulphuric acid $98 \%$ p.a. was used as base chemical; alkaline solutions were prepared from $1 \mathrm{M} \mathrm{KOH}$ Titrisol cartridges. The ethanol used to prepare the solutions was AnalaR NORMAPUR 99.9\% from VWR. The investigated potential denaturing agents were technical grade and used without further purification. All solutions were made using ultrapure water $\left(0.055 \mu \mathrm{S} \mathrm{cm}^{-1}\right)$.

In the graphs, unless otherwise stated, the current is referenced to the real surface area of the working electrode, that is, as current density. The real surface area of the electrodes was determined from the hydrogen adsorption charge according to the method described in [5].

To investigate more fuel cell relevant commercial catalysts, inks of these catalysts were prepared and applied to inert titanium support electrodes. In acidic medium a Nafion bound platinum-tin catalyst from BASF Fuel Cells Inc. $(\mathrm{PtSn} / \mathrm{C} 40 \%)$ was used, in alkaline environment a Teflon bound nonplatinum catalyst supplied by Acta S.p.A. (Hypermec3) was employed.

In order to learn more about the oxidation products, differential electrochemical mass spectroscopy (DEMS) and gas chromatographic analyses (GC/MS) were performed. With respect to DEMS the setup described in [6] was used. In brief, it consisted of an electrochemical flow cell with a Kel-F body connected to the mass spectrometer Balzers QMS 200. A Teflon membrane sputter deposited with platinum served simultaneously as working electrode and inlet to the vacuum system of the mass spectrometer. The electrolyte was supplied hydrostatically from electrolyte reservoirs which allowed the exchange of electrolyte solutions. The mass spectrometer and the potentiostat Gamry Reference 600 were operated simultaneously with custom made LabVIEW software.

For the fuel cell tests, single cells were assembled depending on the working conditions using either Nafion115 membranes from DuPont or Fumasep FAA membranes from FuMA-Tech. For the acidic medium, a custom made $\mathrm{PtSn}+\mathrm{PtRu}$ anode catalyst was applied while an Acta Hypermec anode was used in alkaline medium.

\section{Results}

As a starting point, three interesting substances were chosen from the variety of chemicals which are used as denaturing agents for different purposes.

The first substance is fusel oil which is a by-product of the bioethanol distillation. Fusel oil consists of a variety of higher complex alcohols, esters, and ethers. It is similar to colophony or shellac which are already approved in the EU as denaturing agents for the purpose of complete denaturing. Furthermore, the use of fusel oil as denaturing agent would turn it from a waste product to a valuable side-product of the ethanol distillation.

The second potential denaturing agent is tert-butyl ethyl ether (ETBE). ETBE has some structural similarity to ethanol and is already approved as denaturing agent.

Denatomium benzoate (phenylmethyl-[2-[(2,6-dimethylphenyl)amino]-2-oxoethyl]-diethylammonium benzoate, Bitrex) is one of the most widely used substances for denaturing. However, in Germany, Bitrex is only approved for the cosmetics sector as adjuvant to a denaturing agent. Due to its extreme bitterness, only small amounts of Bitrex are needed to make ethanol inedible.

Figure 1 shows the chemical structures of ETBE and Bitrex. While Bitrex is a rather bulky molecule containing a quaternary ammonium structure and an amide group, ETBE is a comparatively simpler ether.

Figure 2 shows the electrochemical behaviour of ETBE, fusel oil and Bitrex in acidic and alkaline medium. As fusel oil is poorly soluble in aqueous media, the aqueous extracts of fusel oil/electrolyte mixtures were analysed.

In the acidic medium the oxidation of ETBE results in two peaks situated at $0.9 \mathrm{~V}$ and $1.3 \mathrm{~V}$ versus RHE. In the 


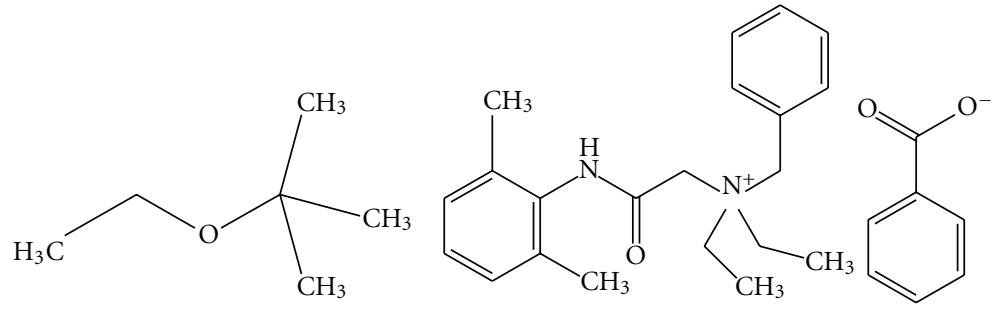

(a)

(b)

FIGURE 1: Chemical structures of tert-butyl ethyl ether (ETBE) (a) and denatonium benzoate (phenylmethyl-[2-[(2,6-dimethylphenyl)amino]-2-oxoethyl]-diethylammonium benzoate, Bitrex) (b).

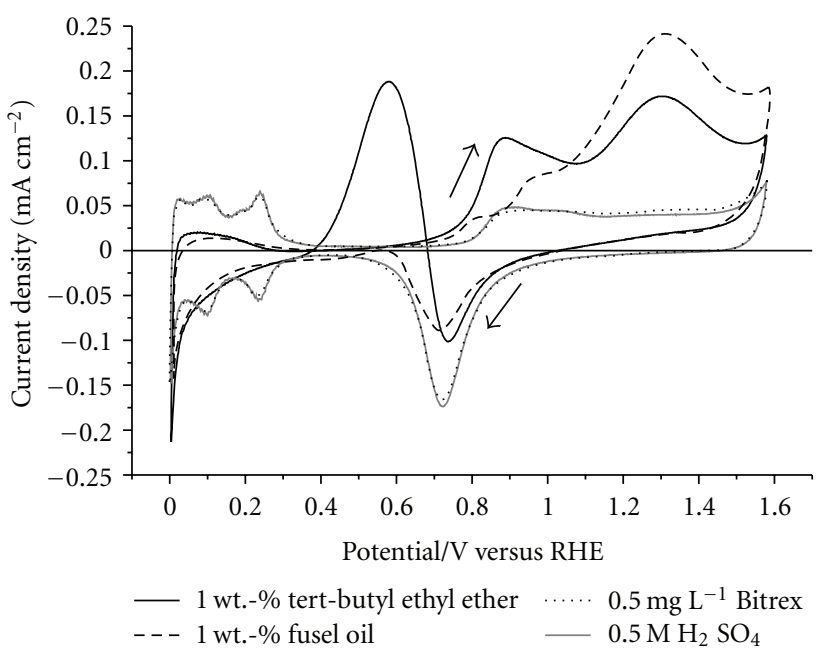

(a)

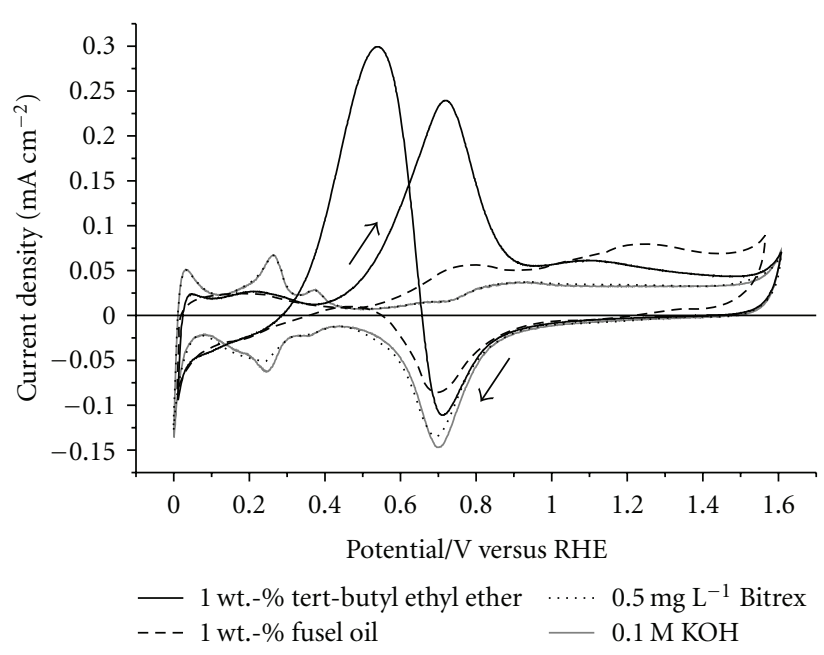

(b)

FIGURE 2: Electrochemical behaviour of potential denaturing agents in $0.5 \mathrm{M} \mathrm{H}_{2} \mathrm{SO}_{4}$ (a) and $0.1 \mathrm{M} \mathrm{KOH}$ (b). 1 wt.- $\%$ ETBE (line), 1 wt.- $\%$ fusel oil (dashed), $0.5 \mathrm{mg} \mathrm{L}^{-1}$ Bitrex (dotted), and background (grey line). Scan rate $50 \mathrm{mV} \mathrm{s}^{-1}$.

cathodic scan of the cyclic voltammogram, another oxidation peak is visible at approximately $0.6 \mathrm{~V}$ versus RHE. The hydrogen adsorption and desorption peaks are widely blocked. This cyclovoltammetric behaviour qualitatively resembles the one of ethanol in sulphuric acid. For fusel oil, the hydrogen adsorption and desorption is even more hindered. In the anodic scan, fusel oil can be oxidised in a main peak located at $1.3 \mathrm{~V}$ versus RHE. In the cathodic scan, a small reduction wave is discernible at $0.72 \mathrm{~V}$ versus RHE; however, this does not lead to a reoxidation wave. In the case of Bitrex, the cyclic voltammogram does not appear to change compared to the background voltammogram. This is due to the fact that the Bitrex concentration in the electrolyte is very low $\left(0.5 \mathrm{mg} \mathrm{L}^{-1}\right)$ [7]. However, with respect to the purpose as denaturing agent, the concentration of Bitrex is supposed to be very low.

In alkaline medium the situation is similar. With one oxidation peak in the anodic and one in the cathodic scan, ETBE shows a similar behaviour as ethanol in alkaline medium. Fusel oil is mainly oxidised at higher potentials and Bitrex does not seem to differ from the basic voltammetry scan too much.
Figure 3 shows the influence of the respective denaturing agent on the oxidation of ethanol. In acidic environment (Figure 3(a)), the cyclic voltammograms for ethanol and ethanol denatured with Bitrex show almost the same current densities. Denaturing ethanol with 0.24 wt.-\% of ETBE causes slightly lower current densities compared to pure ethanol. This trend is strongly pronounced for fusel oil. The current densities for the ethanol oxidation drop drastically, especially in the potential region between $0.5 \mathrm{~V}$ and $1.1 \mathrm{~V}$ versus RHE.

In alkaline medium (Figure 3(b)), the ethanol solution denatured with ETBE shows the smallest deviation from the cyclic voltammogram in undenatured ethanol solution. Bitrex as denaturing agent causes slight losses in current density while fusel oil hinders the ethanol conversion again severely.

Taking into account the results obtained above, fusel oil was considered incompatible with the use as denaturing agent for DEFC. Fusel oil adsorbs strongly onto platinum, in alkaline medium it is even impossible to reestablish the clean platinum surface by continuous potential cycling of the working electrode in fresh base electrolyte. Furthermore, 


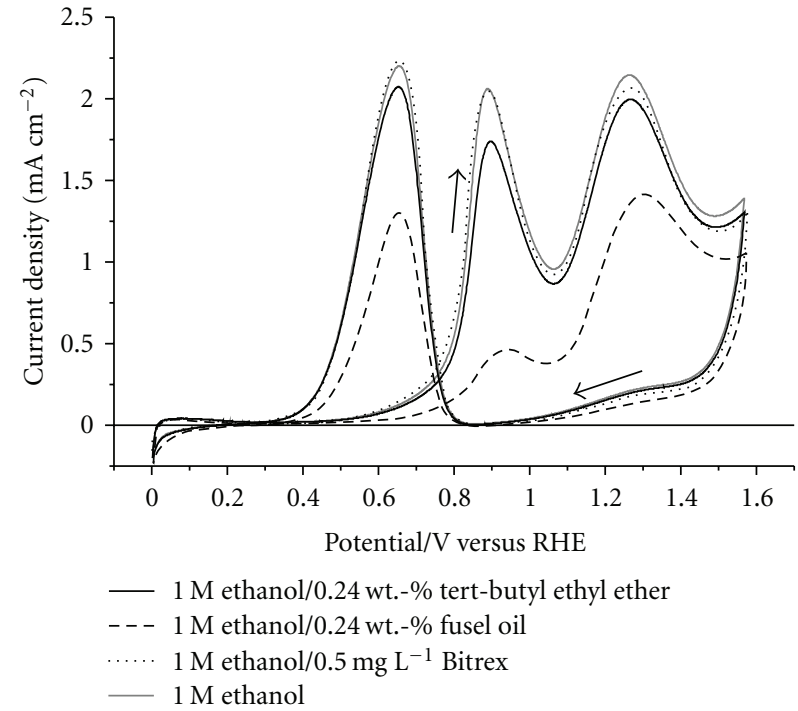

(a)

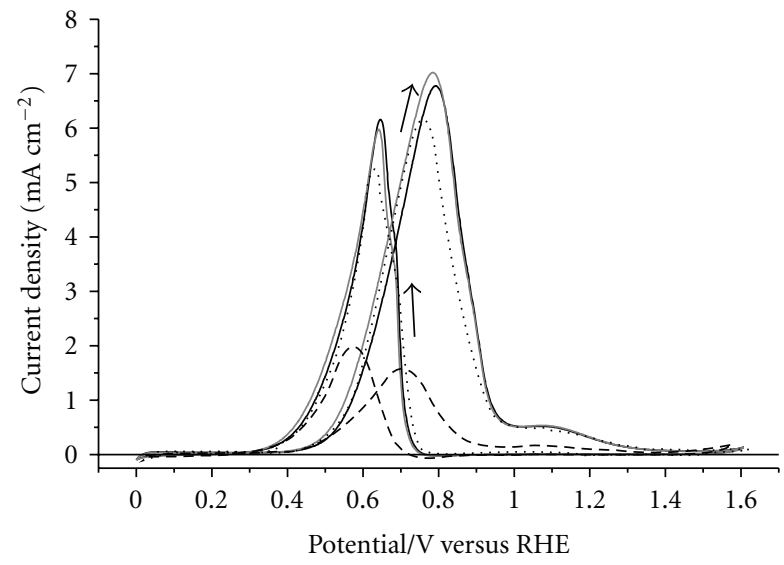

$\begin{array}{ll}\text { - } & 1 \mathrm{M} \text { ethanol } / 0.24 \mathrm{wt} .-\% \text { tert-butyl ethyl ether } \\ --- & 1 \mathrm{M} \text { ethanol } / 0.24 \mathrm{wt} . \% \text { fusel oil } \\ \ldots \ldots & 1 \mathrm{M} \text { ethanol } / 0.5 \mathrm{mg} \mathrm{L}^{-1} \text { Bitrex } \\ \text { - } 1 \mathrm{M} \text { ethanol }\end{array}$

(b)

Figure 3: Cyclic voltammetry of ethanol and denatured ethanol solutions in $0.5 \mathrm{M} \mathrm{H}_{2} \mathrm{SO}_{4}$ (a) and $0.1 \mathrm{M} \mathrm{KOH}$ (b). $1 \mathrm{M}$ ethanol + 0.24 wt.-\% ETBE (line), $1 \mathrm{M}$ ethanol + 0.24 wt. $\%$ fusel oil (dashed), and $1 \mathrm{M}$ ethanol $+0.5 \mathrm{mg} \mathrm{L}^{-1}$ Bitrex (dotted) and $1 \mathrm{M}$ ethanol (grey line). Scan rate $50 \mathrm{mV} \mathrm{s}^{-1}$.

besides its poor solubility in aqueous media, fusel oil hinders the ethanol conversion dramatically in both acidic and alkaline environment.

ETBE on the other hand seems to be converted in acidic and alkaline media. In both media, the cyclic voltammetry of ETBE qualitatively resembles the one of ethanol. Compared with pure ethanol, the current densities of an ethanol mixture with ETBE are slightly reduced in sulphuric acid. However, this reduction is still tolerable. In alkaline medium, however, there seems to be no appreciable difference between pure ethanol and the one denatured with ETBE.

In the concentration range relevant for the possible use as denaturing agent, Bitrex seems to be almost inert in acidic and alkaline environments. Furthermore, in acidic medium, the ethanol conversion is not affected at all by adding Bitrex to the ethanol solution. However, in alkaline medium the current densities of an ethanol solution denatured with Bitrex are somewhat reduced compared to pure ethanol.

As ETBE seems to be the only tested potential denaturing agent which is notably converted at platinum, electrolyses were conducted in order to learn more about its electrochemical reaction. A sample of the electrolyte containing the potential denaturing agent was analysed before and after the electrolysis with GC/MS.

Table 1 shows the main components of ETBE containing electrolytes as identified and quantified by GC/MS.

Table 1 shows that the starting substances are clearly reduced by the electrolyses. An accumulation of nonvolatile products could not be detected. As main contaminants of the technical grade ETBE, the substances ethanol, tert-butanol, and acetaldehyde could be identified.

In order to learn more about the volatile products of the ETBE conversion, differential electrochemical mass spectroscopy (DEMS) was performed. As shown in Figure 4, the volatile products detected with DEMS in acidic and alkaline environments are almost the same as for ethanol. Acetaldehyde and carbon dioxide can be identified. The signal for oxygen is usually not present in the decomposition spectrum for ethanol. However, in the case of ETBE this signal might originate from the reduction of peroxides present in the ETBE solution.

The fact that the cyclic voltammograms of ETBE and the results from DEMS are very similar to those of ethanol lead to the assumption that during the electrochemical oxidation of ETBE its ether bond gets broken. In this case the ethanolic fraction could be converted in the same way as ethanol leading to similar voltammetric behaviour and volatile products. However, the further conversion of the remaining tert-butyric species is still unclear. As tert-butanol is not very reactive at platinum, a conversion is at least doubtful. On the other hand the GC/MS results do not point to an accumulation of species to be considered.

As ETBE is a promising candidate as possible denaturing agent for DEFC, and as Bitrex is an adjuvant to a denaturing agent, the next step was to investigate a mixture of ETBE and Bitrex. The advantage here is that the amount of Bitrex that needs to be added is very low, while the amount of the other component of the mixture of denaturing agents can be reduced. While in case of ETBE alone 39.5 grams per litre of ethanol are needed in order to fulfil the denaturing purpose, the same can probably be obtained by adding 8 milligrams of Bitrex and 1.1 grams of ETBE to a litre of ethanol. Thus, the addition of Bitrex to ETBE has a substantial potential to reduce the remaining adverse effects of ETBE on the ethanol conversion by reducing its concentration in the solution.

In Figure 5, the results for ethanol solutions denatured with a mixture of 0.24 wt.- $\%$ ETBE and $0.5 \mathrm{mg} \mathrm{L}^{-1}$ Bitrex are shown. 

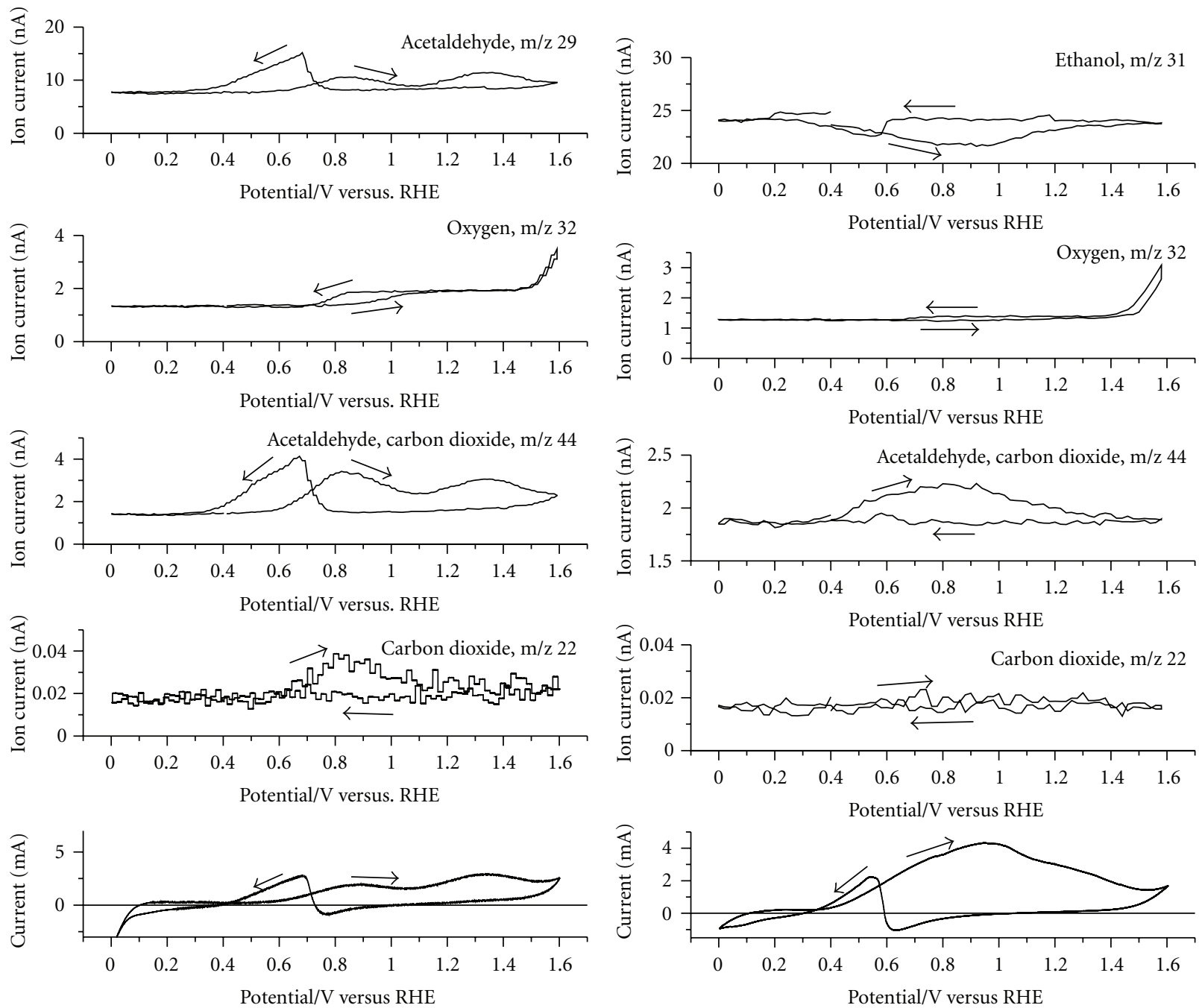

(a)

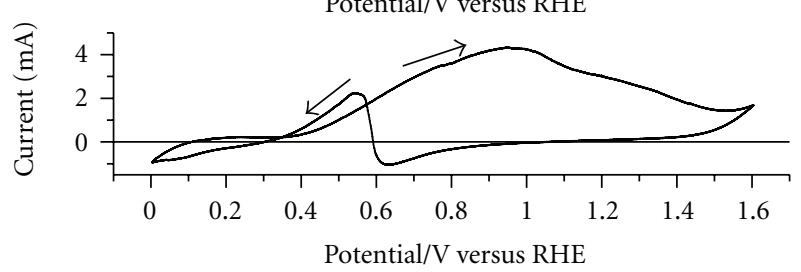

(b)

Figure 4: Mass spectrometric cyclic voltammograms (MSCVs) of 1 wt.- $\%$ ETBE in $0.5 \mathrm{M} \mathrm{H}_{2} \mathrm{SO}_{4}$ (a) and $0.1 \mathrm{M} \mathrm{KOH}$ (b). Mass fragments and assignment of substances as indicated in the graphs. Scan rate $10 \mathrm{mV} \mathrm{s}^{-1}$, flow rate $2.4 \mathrm{~mL} \mathrm{~min}^{-1}$.

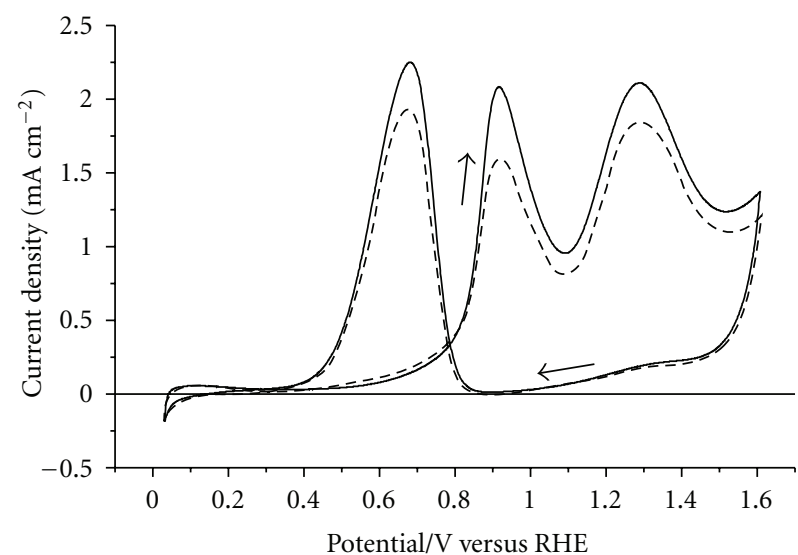

(a)

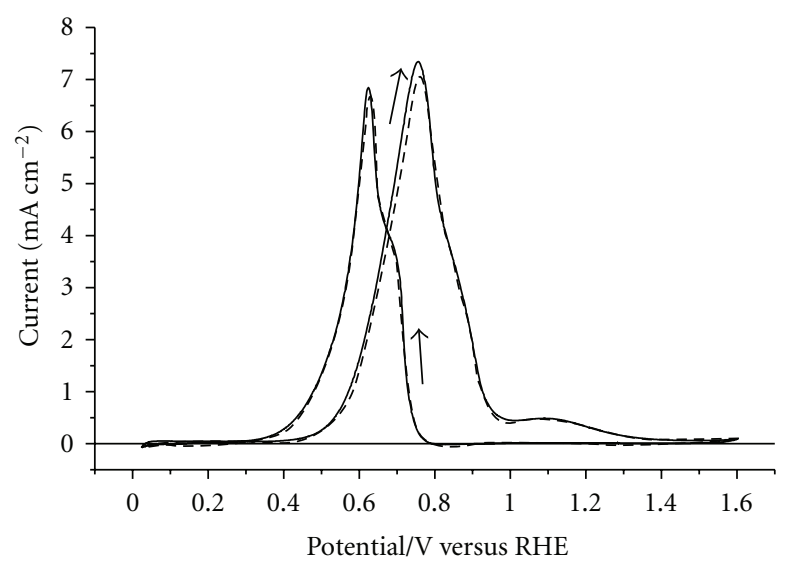

(b)

FIGURE 5: Cyclic voltammetry of ethanol solutions containing a mixture of ETBE and Bitrex in $0.5 \mathrm{M} \mathrm{H}_{2} \mathrm{SO}_{4}$ (a) and $0.1 \mathrm{M} \mathrm{KOH}$ (b). $1 \mathrm{M}$ ethanol (line) and $1 \mathrm{M}$ ethanol + $0.24 \mathrm{wt} .-\% \mathrm{ETBE} / 0.5 \mathrm{mg} \mathrm{L}^{-1}$ Bitrex (dashed). Scan rate $50 \mathrm{mV} \mathrm{s}^{-1}$. 
TABLE 1: Results of the GC/MS analysis of samples containing $1 \mathrm{wt.}$ - $\%$ ETBE before and after the electrolysis at $0.7 \mathrm{~V}$ versus RHE in acidic and alkaline electrolytes.

\begin{tabular}{lcccc}
\hline Electrolyte & $0,5 \mathrm{M} \mathrm{H}_{2} \mathrm{SO}_{4}$ & $0,5 \mathrm{M} \mathrm{H}_{2} \mathrm{SO}_{4}$ & $0,1 \mathrm{M} \mathrm{KOH}$ & - \\
\hline Electrolysis time & - & $1,5 \mathrm{~h}$ & $-1 \mathrm{M} \mathrm{KOH}$ \\
Charge & - & $4,2 \mathrm{mC}$ & 10715 & $24 \mathrm{~h}$ \\
ETBE mg kg-1 & 12512 & 13 & 517 & 2 \\
Ethanol mg kg-1 & 1077 & 536 & 223 & 340 \\
tert-butanol mg kg-1 & 1054 & 239 & 21 & 84 \\
Acetaldehyde mg kg-1 & 44 & $<1$ & $<1$ & $<1$ \\
i-butanol mg kg-1 & 16 & $<1$ & $<1$ & $<1$ \\
Methanol mg kg-1 & $<1$ & $<1$ & $<1$ & $<1$ \\
3-Methyl-1-butanol mg kg-1 & $<1$ & $<1$ & $<1$ \\
2-Methyl-1-butanol mg kg-1 & $<1$ & & $<$ \\
\hline
\end{tabular}

Compared with the cyclic voltammograms in Figure 3, there is no serious difference. This means that the addition of $0.5 \mathrm{mg} \mathrm{L}^{-1}$ Bitrex to the ETBE has no significant negative influence on the electrochemical reactions at platinum.

As the mixture of ETBE and Bitrex still has the potential of reducing the ETBE content, it was also tested at real fuel cell catalysts instead of pure platinum. For the acidic medium a PtSn catalyst from BASF (PtSn/C 40\%, BASF Fuel Cells Inc.) was chosen, while in alkaline medium a platinum-free catalyst on the basis of palladium, cobalt and iron from Acta was employed (Hypermec3, Acta S.p.A.). The respective catalysts were applied to an inert titanium support electrode. In the acidic medium Nafion served as binder, in alkaline environment Teflon was applied.

Figure 6 shows the results in sulphuric acid and potassium hydroxide solution.

At the PtSn catalyst, the performance of the denatured ethanol solution is slightly worse compared to pure ethanol. However, at the platinum-free Acta catalyst, there is almost no difference between pure and denatured ethanol solutions. Only the onset of the oxidation reaction in the anodic potential sweep is slightly delayed.

Figure 7 shows the fuel cell tests in acidic and alkaline environments with ethanol and ethanol denatured with ETBE and Bitrex.

It is very interesting to see that the power density in the acidic fuel cell fed with denatured ethanol is even higher for low current densities than with pure ethanol as fuel. This could not be expected from the electrochemical measurements at the $\mathrm{PtSn}$ catalyst. However, the fuel cell was equipped with a PtSn + PtRu catalyst which obviously enhances the oxidation of the denatured ethanol solution. Pure ethanol can outperform denatured ethanol as fuel only near the peak power density region.

In general, the performance of $9 \mathrm{~mW} \mathrm{~cm}^{-2}$ for an acidic direct ethanol fuel cell with a PtSn $+\mathrm{PtRu}$ anode is not as good as reported in [8]. However, the about ten times higher performance in [8] was achieved at $90^{\circ} \mathrm{C}$ in an optimized system with a metal loading at the anode of $7 \mathrm{mg} \mathrm{cm}^{-2}$ and a platinum cathode $\left(3.7 \mathrm{mg} \mathrm{cm}^{-2}\right)$ supplied by pure oxygen at a pressure of $0.2 \mathrm{MPa}$. Furthermore, a higher ethanol concentration of $1.5 \mathrm{~mol}$ was used in [8]. Especially the lower metal loading at the anode, the use of air instead of pure oxygen at the cathode side, as well as the operation with ambient cathode back pressure, instead of $0.2 \mathrm{MPa}$ cathode back pressure and the lower temperature of $50^{\circ} \mathrm{C}$ may explain the differences in the performance reported in Figure 7(a).

In [9], a current density of approximately $30 \mathrm{~mA} \mathrm{~cm}^{-2}$ at $0.3 \mathrm{~V}$ is reported for an alkaline membrane fuel cell equipped with Acta Hypermec anode and cathode supplied by $1 \mathrm{M}$ ethanol in $1 \mathrm{M}$ potassium hydroxide solution at the anode and $100 \mathrm{sccm}$ oxygen at the cathode at a temperature of $40^{\circ} \mathrm{C}$. This performance is comparable to the approximately $35 \mathrm{~mA} \mathrm{~cm}^{-2}$ at $0.3 \mathrm{~V}$ for the alkaline fuel cell running on pure ethanol as described in Figure 7(b).

In alkaline environment, the performance of the fuel cell fed with denatured ethanol is lower than for the fuel cell fed with pure ethanol. However, the peak power density is only lowered by approximately 10\%, and at lower current densities the difference is even smaller.

\section{Conclusion}

In this study, three substances have been tested towards their use as denaturing agents in direct ethanol fuel cells.

The first substance fusel oil is a waste product of the bioethanol distillation, thus it would be economically attractive to turn it into a valuable side-product by using it as denaturing agent. However, fusel oil adsorbs strongly and in alkaline medium even irreversibly onto the platinum surface, thereby lowering the current densities for the ethanol oxidation tremendously. As fusel oil is furthermore only poorly soluble in aqueous media, it turned out to be incompatible with the use as denaturing agent in DEFC.

Tert-butyl ethyl ether (ETBE) is already approved as denaturing agent in the EU. Furthermore, its chemical structure has some similarities with the one of ethanol. While in acidic environment the current densities obtained with ethanol denatured by ETBE are slightly smaller compared to pure ethanol, especially in alkaline medium, the differences between denatured and pure ethanol are insignificant. The shape of the cyclic voltammograms thereby resembles the one for ethanol. GC/MS analysis and DEMS show that ETBE can be oxidised at platinum. Particularly with DEMS, it could 


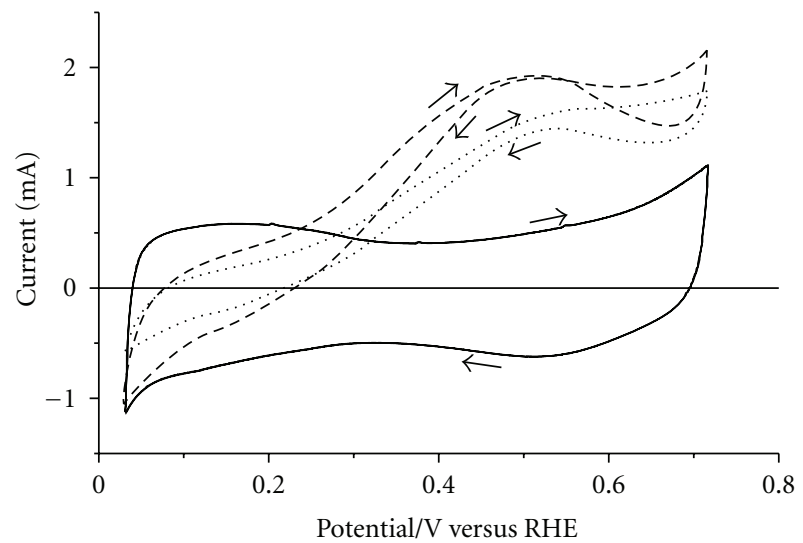

(a)

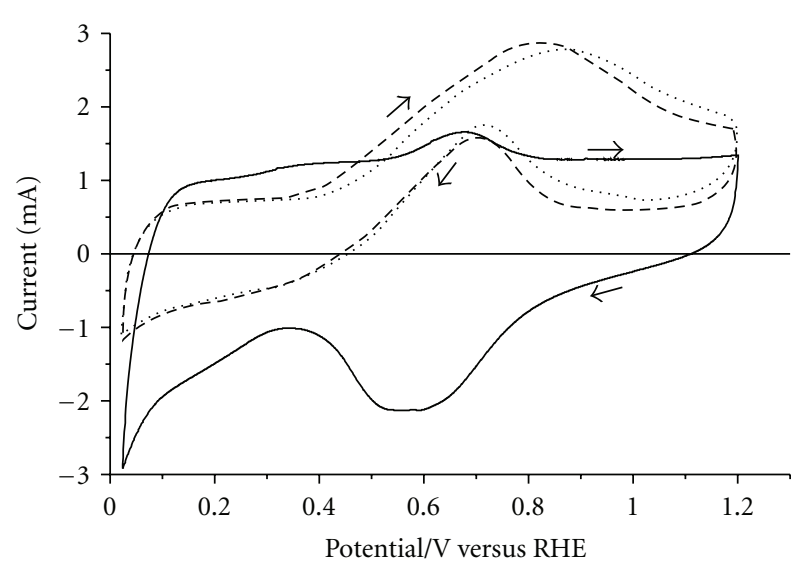

(b)

Figure 6: Cyclic voltammetry of ethanol solutions containing a mixture of ETBE and Bitrex at a PtSn catalyst in $0.5 \mathrm{M} \mathrm{H}_{2} \mathrm{SO}_{4}(\mathrm{a})$ and at a PdCoFe catalyst in $0.1 \mathrm{M} \mathrm{KOH} \mathrm{(b).} \mathrm{Base} \mathrm{electrolyte} \mathrm{(line),} 1 \mathrm{M}$ ethanol (dashed), and $1 \mathrm{M}$ ethanol +0.24 wt.- $\%$ ETBE $/ 0.5 \mathrm{mg} \mathrm{L}{ }^{-1}$ Bitrex (dotted). Scan rate $50 \mathrm{mV} \mathrm{s}^{-1}$.

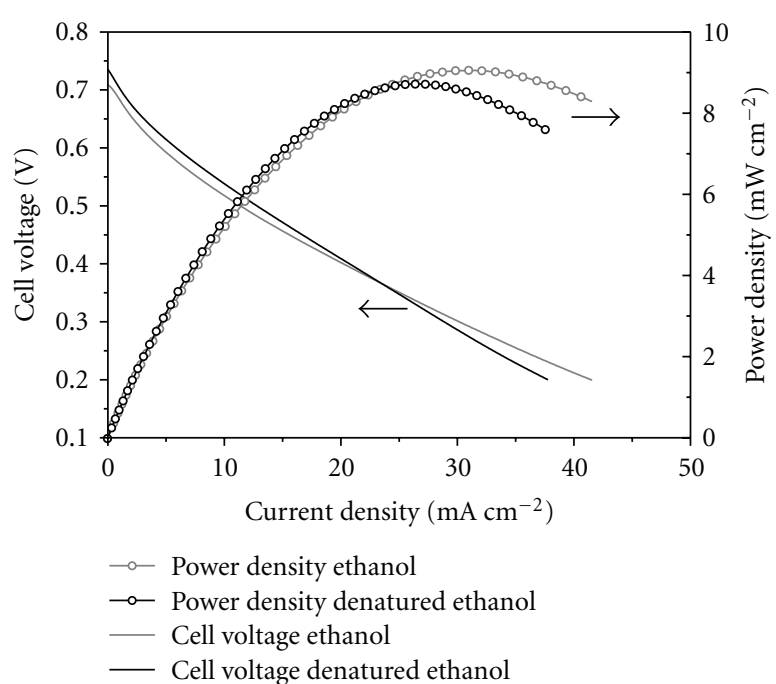

(a)

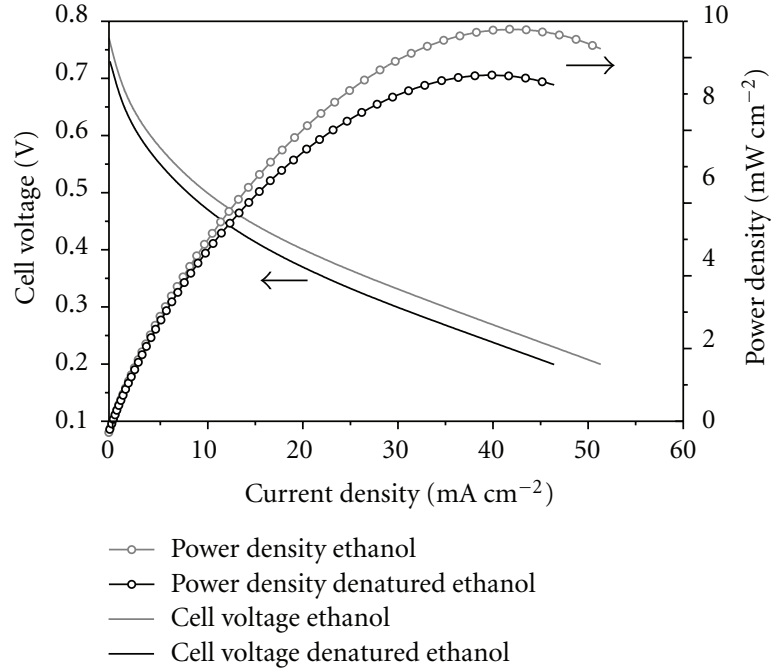

(b)

FIGURE 7: Fuel cell tests of pure ethanol (grey), ethanol solutions containing a mixture of ETBE and Bitrex (black) in acidic (a) and alkaline environment, (b). (a) PtSn + PtRu anode (3.68 mg metal cm ${ }^{-2}$ ), Nafion 115 membrane, and PtCo cathode $\left(2.67 \mathrm{mg} \mathrm{metal} \mathrm{cm}^{-2}\right) .1 \mathrm{~mL} \mathrm{~min}^{-1}$ aqueous $1 \mathrm{M}$ ethanol, $1.4 \mathrm{~L} \mathrm{~min}^{-1}$ air, $50^{\circ} \mathrm{C}$. (b) Acta Hypermec3 anode, Fumasep FAA membrane and Acta Hypermec cathode. 1 mL min ${ }^{-1}$ $10 \%$ ethanol $+10 \% \mathrm{KOH}, 250 \mathrm{~mL} \mathrm{~min}^{-1}$ air, $50^{\circ} \mathrm{C}$.

be shown that the volatile reaction products of ETBE are almost the same as for ethanol, indicating the scission of the ether bond in the ETBE molecule.

Denatonium benzoate (Bitrex) is a widespread adjuvant to a denaturing agent. It could be shown, that in the intended concentrations Bitrex behaves almost inert in acidic and alkaline environment. As the taste of Bitrex is extremely bitter, only very small amounts of Bitrex are needed for the purpose of denaturing. Adding Bitrex as adjuvant to another denaturing agent offers the possibility to lower the content of that denaturing agent. So with the perspective of lowering the ETBE concentration and thereby omitting its adverse effects on the ethanol oxidation especially in acidic environment, a mixture of ETBE and Bitrex was tested.

Ethanol denatured with the mixture of ETBE and Bitrex behaves in the same way as ethanol denatured with just ETBE does. Thus, the addition of Bitrex to ETBE has no negative effect on the electrochemical reactions. Investigations at commercial fuel cell catalysts and in single cell fuel cells reveal that the effects on the performance depend strongly on the catalyst used. For low current densities, an acidic fuel cell with a PtSn + PtRu anode fed with ethanol denatured by a mixture of ETBE and Bitrex could even outperform the same fuel cell configuration running on pure ethanol as fuel. On 
the other hand, the performance loss at peak power density in an alkaline fuel cell fed with denatured ethanol was shown to be about $10 \%$.

Taking into account the presented results it can principally be stated that the mixture of ETBE and Bitrex is a promising candidate as denaturing agent for ethanol as fuel for DEFC. This applies to the acidic medium as well as to the alkaline environment. However, the exact composition of such a mixture of denaturing agents needs to be investigated in cooperation with the customs authorities. Therefore, more work especially in fuel cell testing under standardised conditions needs to be done.

\section{Acknowledgment}

The financial support of parts of this work by the German Federal Ministry of Consumer Protection, Food and Agriculture (BMVEL) under the contract no. 22003507 is hereby gratefully acknowledged.

\section{References}

[1] T. Iwasita, "Fuel cells: spectroscopic studies in the electrocatalysis of alcohol oxidation," Journal of the Brazilian Chemical Society, vol. 13, no. 4, pp. 401-409, 2002.

[2] H. Tang, S. Wang, M. Pan, S. P. Jiang, and Y. Ruan, "Performance of direct methanol fuel cells prepared by hot-pressed MEA and catalyst-coated membrane (CCM)," Electrochimica Acta, vol. 52, no. 11, pp. 3714-3718, 2007.

[3] E. Antolini and E. R. Gonzalez, "Alkaline direct alcohol fuel cells," Journal of Power Sources, vol. 195, no. 11, pp. 3431-3450, 2010.

[4] X. Cheng, Z. Shi, N. Glass et al., "A review of PEM hydrogen fuel cell contamination: impacts, mechanisms, and mitigation," Journal of Power Sources, vol. 165, no. 2, pp. 739-756, 2007.

[5] T. Biegler, D. A. J. Rand, and R. Woods, "Limiting oxygen coverage on platinized platinum; relevance to determination of real platinum area by hydrogen adsorption," Journal of Electroanalytical Chemistry, vol. 29, no. 2, pp. 269-277, 1971.

[6] C. Cremers, D. Bayer, B. Kintzel et al., "Investigation on denaturing agents for use with ethanol in direct ethanol fuel cells (DEFC)," ECS Transactions, vol. 17, no. 1, pp. 517-524.

[7] D. Bayer, B. Kintzel, M. Joos, C. Cremers, and J. Tübke, Extended Abstracts of the First International Conference on Materials for Energy, vol. 11, 2010, Book A.

[8] Q. Wang, G. Q. Sun, L. Cao et al., "High performance direct ethanol fuel cell with double-layered anode catalyst layer," Journal of Power Sources, vol. 177, no. 1, pp. 142-147, 2008.

[9] Y. S. Li, T. S. Zhao, and Z. X. Liang, "Effect of polymer binders in anode catalyst layer on performance of alkaline direct ethanol fuel cells," Journal of Power Sources, vol. 190, no. 2, pp. 223-229, 2009. 


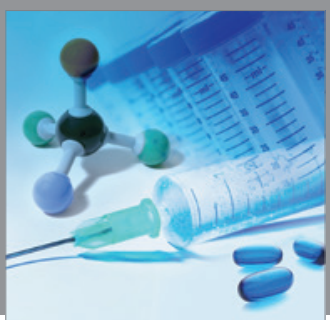

International Journal of

Medicinal Chemistry

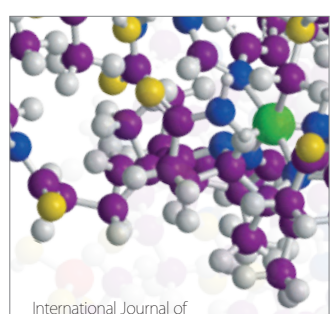

Carbohydrate Chemistry

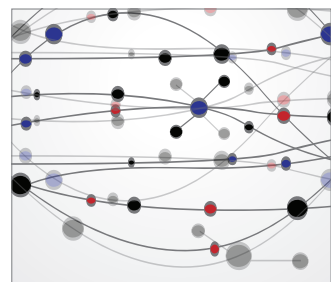

The Scientific World Journal
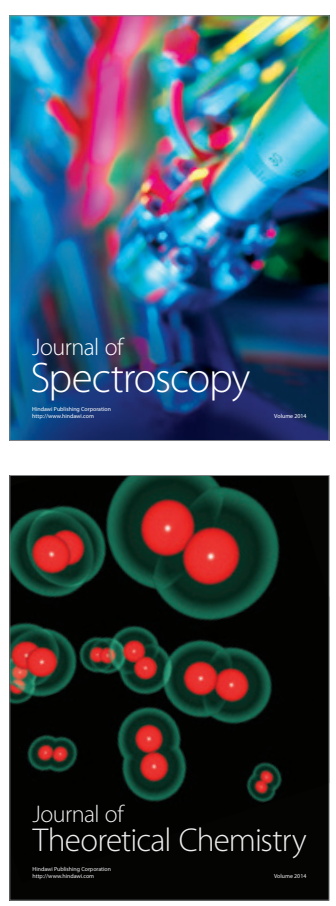
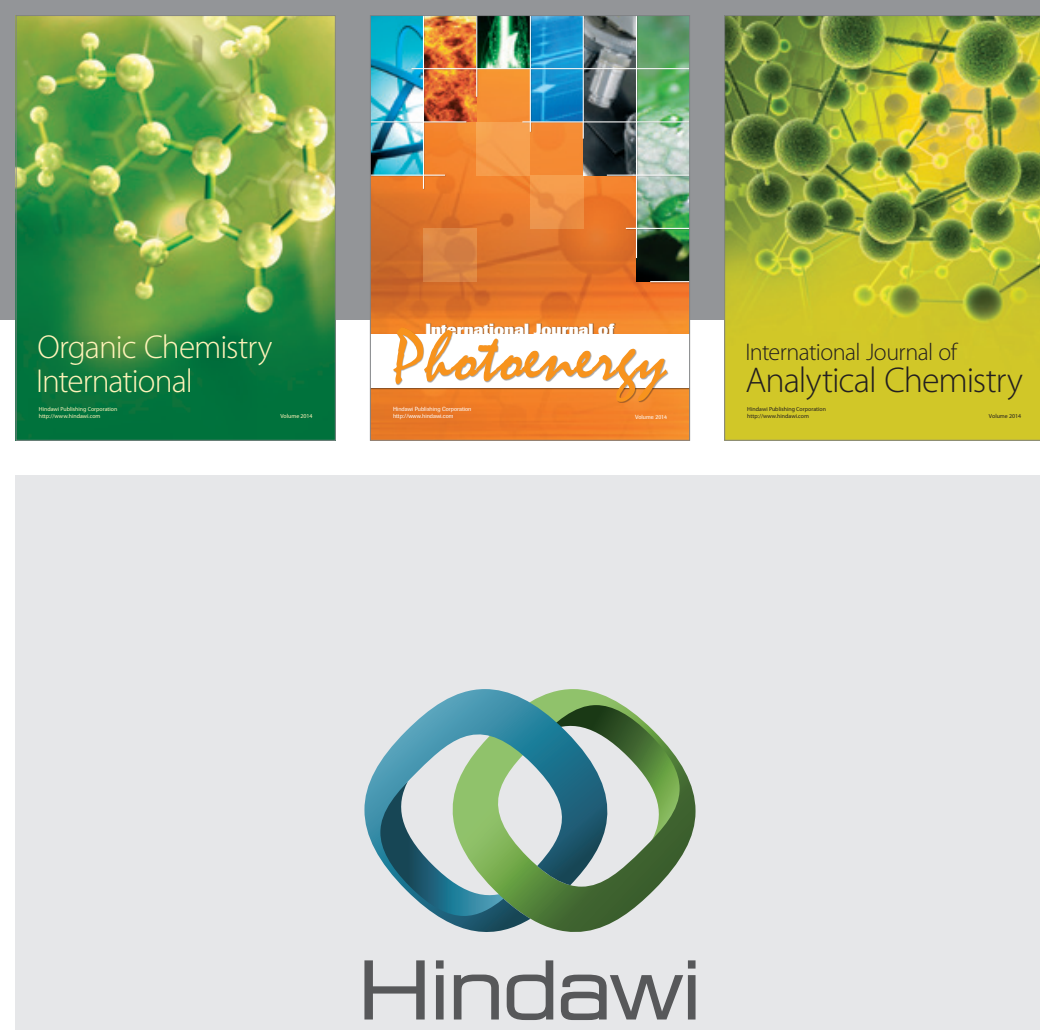

Submit your manuscripts at

http://www.hindawi.com
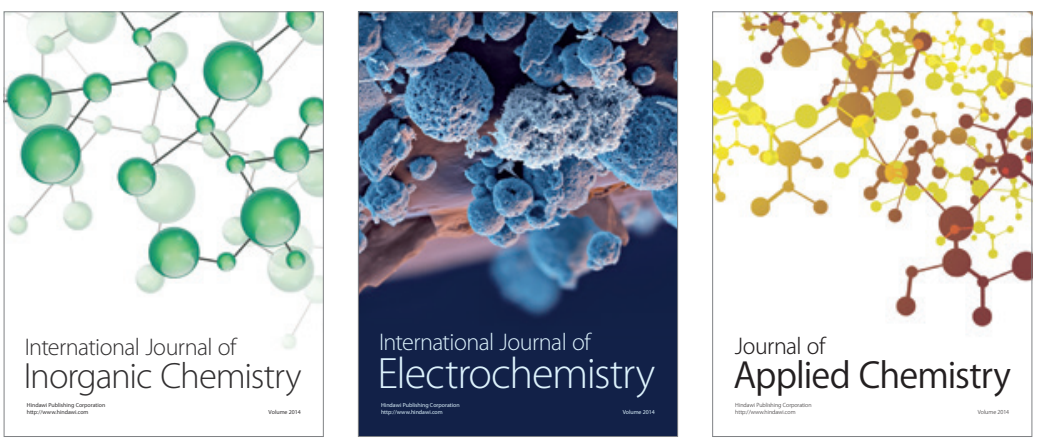

Journal of

Applied Chemistry
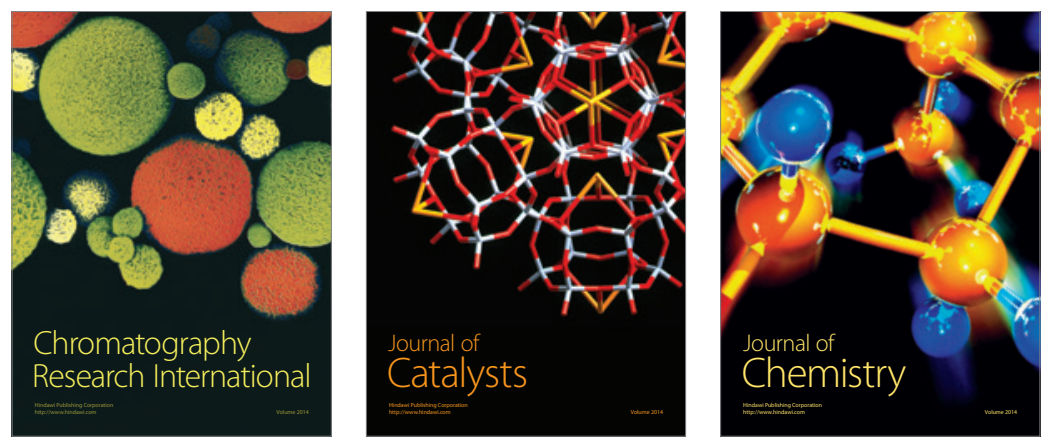
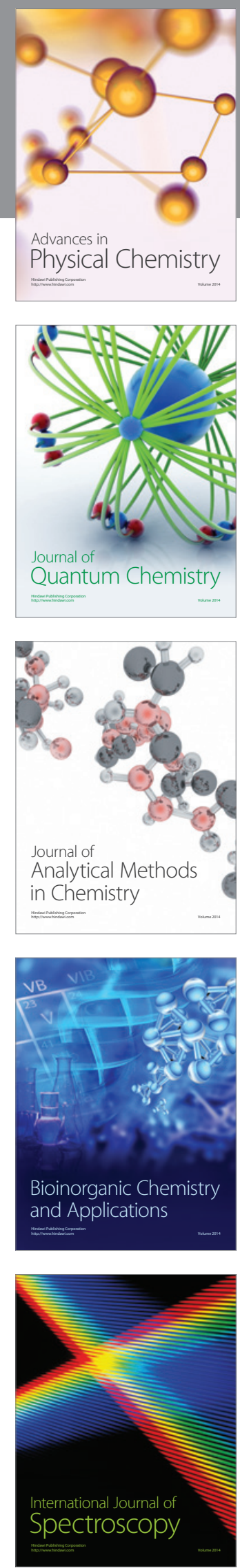